\title{
Enrique González Martínez en su Plenitud
}

$\mathrm{F}^{\mathrm{N}}$ otro estudio mío, incorporado a la edición española L (1925) de El Romero alucinado, estudio que se publicó por primera vez en la "Revista de Occidente" con el título de "El cóndor, el cisne y el buho", he señalado la correspondencia que guardan entre sí los diversos libros de Enrique González Martínez, su perfecta continuidad, bien visible ahora en la edición colectiva que reúne en tres tomos la obra poética completa - descartadas por el autor algunas poesías, quién sabe si todas ellas con criterio absolutamente justo.

El segundo volumen comprende cuatro libros, Parábolas $y$ otros poemas, La palabra del viento, El romero alucinado y Las señales furtivas, que van de 1917 a 1923. En ellos se concentra la plenitud de un gran poeta. La plenitud, entiéndase bien, ya alcanzada desde Silenter, es que por primera vez abre sus ojos vigilantes el buho, y levantada todavía en los libros posteriores a éstos que se suman en el volumen segundo, con las notas graves, de sabor dantesco, en que se evocan sombras de muertos queridos. Ciñéndome a los cuatro libros mentados, observo en ellos la maestría de expresión, la serenidad espiritual, que son cualidades típicas en el gran poeta de México.

Nos dejan ver las Parábolas cierta actitud de moralista, que se ajusta perfectamente al cuerpo la vestidura poética. El magisterio adopta temas llenos de dramaticidad, de misterio a veces, y no le vendría bien la andadura didáctica. El 
poeta sale fuera de sí y su emoción se incorpora en figuras que no son sino dobles del poeta mismo, sueños de su imaginación en los que, a cada instante, se despliega en lo que constituye su íntima personalidad; el hombre en camino, a través de la vida: "La vida es un camino" dice en el primer verso. $Y$ el poeta es un hombre como tantos otros, reconocible en éste o en aquél, como ellos vienen a reconocerse, suprema síntesis de todos, en el poeta. Este no les lleva a los demás otra ventaja, si ello es ventaja, que la sensibilidad merced a la cual se siente ligado a todo, hallándose en el punto de cruce de tantas misteriosas llamadas, de tantas sugestiones recónditas, de tantas "señales furtivas", inadvertidas para los otros, y que llegan a él sin que sepa, de pronto, a qué le empujan, qué le predicen, cuál puede ser su plena significación:

\section{Atan hebras sutiles a las cosas distantes...}

Y ello humildemente, sin alarde, ni oratoria, ni super-nada; humilde, pero profundamente. En el epígrafe que imaginó el poeta "para un libro futuro" (en La palabra del viento) hallamos su manera de ser, que se aplica por igual a sus realizaciones pasadas y a lo que había de lucir más tarde en su poesía:

\section{...no hay en sus hojas nadia}

que no sea la frágil urdimbre de otras vidas...

la frase salta a-veces palpitante y desnuda;

otras, con el ropaje del símbolo se escuda...

este libro no enseña, ni conforta, ni guía,

y la inquietud que esconde es solamente mía;

mas en mis versos flota, diafanidad o arcano,

la vida, que es de todos. Quien lea, no se asombre

de hallar en mis poemas la integridad de un hombre, sin nada que no sea profundamente humano.

El libro futuro cuya fisonomía trazaban estos versos bien podría ser el que encerrara la obra definitiva de Enrique González Martinez. Nada, en los tres volúmenes en que ahora se concentra, escapa de esta declaración, hecha, además, con un habla sencilla en una poesía cuya perfección se cifra en la 
ausencia de aprestos retóricos, así en la elocución como en el corte del verso.

Las más de las poesías de González Martínez en éste su período de plenitud, se desarrollan en endecasílabos o alejandrinos, ya en estrofas regulares, ya en silva o combinaciones libres con versos menores, y en un ritmo que no está marcado por la rotundidad del acento, sino por el sentido que capta el vocablo, con una rima que no persigue alardes de riqueza, sin que por ello desdeñe la palabra escogida. Endecasílabo o alejandrino ya no cantados ni escandidos, sino hablados; no eluden el encuentro de vocales en el hemistiquio y sólo evitan, visiblemente, una tacha: la afectación.

Culmina aquí una manera que viene a refundir la poética del liamado modernismo con una sencillez en que se acendra su mayor eficacia. El poeta se ha despojado voluntariamente de oropeles y relumbrones. Ha "torcido el cuello al cisne", borrado de su blasón ese símbolo. Quizá no sería desacertado el ver en su manera la culminación de algo que perseguían en pleno siglo XIX nobles ingenios, capaces de entrever como cualidad suprema esta sencillez expresiva, pero no de apartarse de su natural pendiente prosaica; anhelosos de ser "de su tiempo", sin caer en la cuenta de que el tiempo de los poetas no es una fecha determinada sino una abstracción. Relojes de hora exacta, la marcan, con abstracción del día.

De las composiciones que forman este segundo volumen, podría decirse, en su mayoría, algo así: tanto son de hoy como de mañana o de ayer. Con lo cual no desdeño la poesía que lieva fuertemente su marca temporal, que, realizada en plenitud de poderío poético, viene a ser eterna; subrayo, únicamente, la cualidad que distingue, a mi ver, la de Enrique González Martínez, comparada, por ejemplo, con la de otros poetas mexicanos no menores - ni mayores tampoco: en estas cosas no hay medida-, pero en los que se acusa fuertemente Ia circunstancia: un Gutiérrez Nájera, un Amado Nervo.

Lo que se advierte, en la trayectoria de los cuatro libros encerrados en este tomo, es el paso lento y gradual de una actitud severa y majestuosa a otra más familiar, en que has- 
ta la métrica gusta de aceptar ritmos juguetones, andaduras rápidas, juegos de pies quebrados y rimas traviesas, asuntos frívolos, imaginaciones aventureras: todo ello sin perder la gracia esencial de la serenidad humana. He señalado también, antes de ahora, cómo en un libro se hallan los gérmenes de otro; y aquí tenemos El romero alucinado, que antes de ser título de libro lo fué de poesía en La palabra del viento:

romero,

dí si miras la luna o el sendero...

No ha refundido González Martínez sus libros, al reunirlos en colección, $y$ ha hecho bien, dejando esas huellas visibles del paso de su inspiración fecunda, que nace de sí misma, se prolonga y renueva, dando fe de persistencia y sinceridad. Los lectores de sus poemas últimos, posteriores a los coleccionados en los tres tomos definitivos, hallarán en los comienzos de Las señales furtivas una composición, "Viaje aéreo", que anticipa cierta graciosa fantasía recientísima:

¿Bajaremos de un astro como de un cuarto piso de aquí a veinte centurias?...

El segundo volumen de Poesía, es, como dije al principio, de plenitud; pero esta plenitud no implica un término ni anuncia la proximidad de una decadencia. Antes al contrario, el dolor ha de abrirle todavía horizontes más amplios, ha de comunicarle acentos más hondos. No vendrá a dar personalidad a un poeta que ha logrado ya la suya con caracteres de permanencia; vendrá, en un arte dueño de sí, a ser como sublimación purificadora, sin cambiar esencialmente la manera, ni hacerla más humana, porque así lo fué desde el comien. zo, pero a darle un vibración todavía más comunicativa. $Y$ no es que en los versos siguientes se haga exhibición de dolores. No cambia la voz, cambia el tono. Ya no ha de ser este caminar sereno, esta experiencia del vivir, estas veras graves - estas burlas ligeras, sino la presencia efectiva de lo que prueba el temple del espíritu, no induciendo a lástima o condolencia, sino despertando en el alma la sensación de comuni- 
dad en el dolor, de remembranza o aviso, de hermandad, en suma.

Contigo va mi corazón, contigo

que oyes la misma voz bajo ol doliente

signo de las estrellas...

đecía ya González Martínez en la "Parábola del hermano".

Enrique Díez-Canedo. 
